
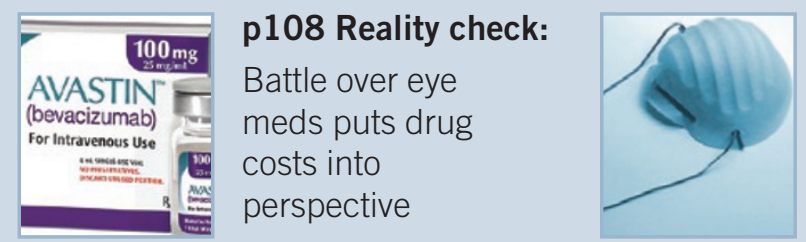

p109 Last resort:

Patients don't

always comply

with quarantine

measures

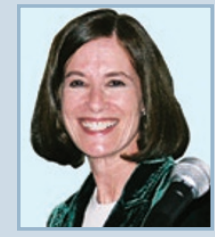

p112 Voicing concern:

Frankie Trull

speaks out

against animal

extremists

\title{
Europe pledges billions to solve its drug development woes
}

When the Danish biopharmaceutical company Action Pharma incorporated in May 2000, it had four academic founders and AP214 - an anti-inflammatory drug candidate designed to prevent organ failure after heart surgery. However, despite the promise of AP214 and the scientific credentials of its creators, Action Pharma had a tough time attracting investors.

To stay afloat with only a small sum of cash, Torbjörn Bjerke and his fellow founding partners "built the company almost on a virtual base," he recalls. By this Bjerke means that the start-up depended largely on contract research organizations to further develop AP214 and its other candidate compounds. In a massive round of venture capital funding last month, Action Pharma raised $€ 15$ million (\$22 million), enough to help it conduct more in-house testing. Still, seven years is a long time to wait for big-ticket investors. "We would have had better opportunities to attract more money, and faster, if we were located in the US," Bjerke says.

For the last decade, emerging biomedical companies in Europe such as Action Pharma have all met the same roadblock to commercial success: eroding interest from venture capitalists. European investors are much more risk averse than their American counterparts, says Robin Davison, an analyst at Edison Investment Research in London. "It's a less entrepreneurial world here," he says. "US venture capital is more established, with larger players.”

Moreover, researchers in the US have a "distinct advantage over Europeans in the way they can move easily between academia and business," says Christopher-Paul Milne, associate director of the Tufts Center for the Study of Drug Development in Boston. The center recently reported that of all the new active medical substances produced globally from 2003 to 2006, $55 \%$ were first launched in the US, compared to just $17 \%$ in Europe. According to the European Federation of Pharmaceutical Industries and Associations (EFPIA) - a trade association representing the industry interests-the US outspent Europe on pharmaceutical research and development by $\$ 3.6$ billion in 2005 .

To try to close this gap, the European Commission and the large pharmaceutical companies within the EFPIA created the

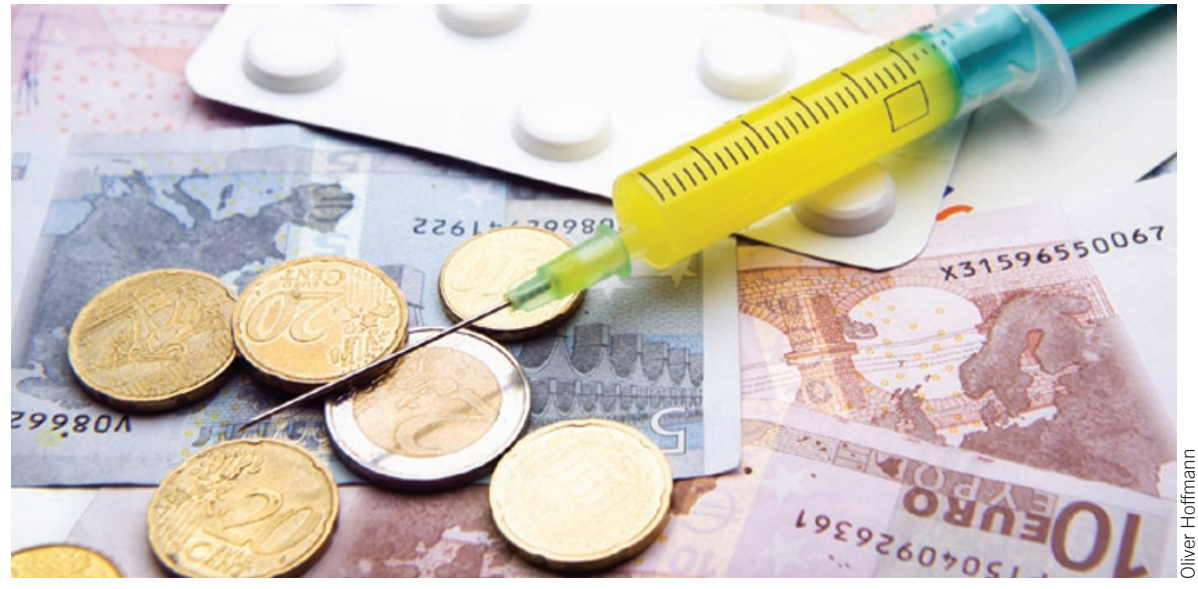

Seeking change: EU companies want more funding for medical research.

Innovative Medicines Initiative (IMI). The six-year, $€ 2$ billion initiative aims to spur investment by "addressing the bottlenecks of drug development," says Carlo Incerti, head of research and development in Europe for the biotechnology giant Genzyme and member of the IMI's governing board.

Funded half by the European Commission and half by in-kind contributions from EFPIA members, the IMI will provide financial support for research conducted by small- and mediumsized enterprises, universities and other nonprofit public entities. The EU's Council of Ministers formally adopted the initiative on 20 December 2007. By late February, the IMI hopes to have a new Brussels office open and ready to accept funding proposals; if all goes well, the actual research will be underway by November.

The 2008 proposals will fall under about 20 specific research topics chosen by the IMI board and will be focused on 'precompetitive' stages of drug development, such as identifying biomarkers for specific diseases. A scientific committee, with members nominated by EU member states, will review IMI proposals and select which ones will receive funding.

Large pharmaceutical companies supported the partnership partly because of what Incerti calls "a shared societal responsibility for Europe." But Simon Goodall, a partner at the Boston Consulting Group, notes that these large companies will probably gain from what's learned from the IMI-funded research by having improved access to the discovery process. Identifying accurate biomarkers of specific diseases, for instance, would help in expediting the future development of a host of drugs meant to treat those diseases. "They're very interested in exploring any new way of radically reinventing the process," he says.

Incerti says that the 35-employee IMI will be run "with the efficiency of a private company." Still, some outsiders raise their eyebrows at the idea of fostering speedy drug development with the creation of a new government bureaucracy. "That's the trouble with the EU," Davison says. "You're trying to reach a consensus of 27 different nations, each with different ideas of where the money should be spent." Indeed, it has already taken three years for the IMI to be approved.

Most pharmaceutical market analysts say that increased government funding alone is unlikely to create sweeping changes in the global research and development investment landscape. The restrictive price controls on drugs in Europe make it a far less attractive end market than the US. "Given the size of the gap, no amount of money from a public-private partnership will directly close it," Goodall says. He adds that it will take some time to know whether the IMI seed money will succeed in encouraging venture capital investment in European drug development. "We're talking about stuff here that takes place over decades, not years."

Virginia Hughes, New York 